Hотсніn, J. E. (1955). J. gen. Microbiol. 13, 185-189.

\title{
The Use of Ammonium Sulphate in the Production of Lysates of Staphylococcus Phage $\mathrm{K}$ of High Titre
}

\author{
By J. E. HOTCHIN* \\ National Institute for Medical Research, Mill Hill, London, N.W. 7
}

SUMMARY: In the production of high titre staphylococcus phage $\mathrm{K}$ lysates from concentrated liquid bacterial cultures the upper limit of phage concentration appears to be at about $10^{10}$ particles $/ \mathrm{ml}$. This concentration, the 'ceiling titre', can be raised to $4 \times 10^{11} \mathrm{particles} / \mathrm{ml}$. by the addition of ammonium sulphate to the medium after phage infection. It is concluded that this effect depends upon the ability of ammonium sulphate to lower the rate of adsorption of phage upon host cells, thus preventing a high rate of phage loss by adsorption and inactivation towards the end of lysis. The possibility is discussed that this mechanism may explain some puzzling observations in lysing systems.

In the course of experiments with staphylococcus phage $\mathbf{K}$, large amounts of bacteriophage were required for purification (Hotchin, 1954); for this, attempts were made to improve the phage yield above that usually obtained in broth lysates. It was noticed that in a rich medium aeration was the limiting factor for high bacterial growth rate. However, when improved methods of aeration were used, although the bacterial growth (measured turbidimetrically) was considerably increased, corresponding increases in the phage titre were not obtained. Even when conditions of phage inoculation (e.g. growth phase of host cells, infective ratio) were varied widely, there appeared to be an upper limit ('ceiling titre') of about $10^{10}$ plaque-forming units $/ \mathrm{ml}$., above which the phage concentration did not rise, in spite of complete lysis of very dense bacterial cultures. It seemed probable that under these conditions at the ceiling titre, phage was being lost at a rate approximating that at which it was being formed. Adsorption to an inactivating agent (possibly bacterial cells) was considered to be the most likely reason for phage loss, and experiments were conducted to attempt to prevent this loss and to test the hypothesis.

\section{METHODS}

Organisms and medium. The Oxford strain of Staphylococcus aureus, NCTC 6571, and staphylococcus bacteriophage $\mathrm{K}$ were used throughout. Hartley tryptic digest broth was used as nutrient medium. Ammonium sulphate was 'Analar' grade.

Bacteriophage assay. This was made by plaque counts on the surface of nutrient agar $(1 \%)$ plates.

* Present address: Department of Bacteriology and Immunology, University of British Columbia, Vancouver, B.C., Canada. 


\section{RESULTS}

Specific antibacterial serum was tested in an attempt to prevent adsorption of progeny phage upon other infected cells of the culture which had not yet lysed. The agglutination titre of the serum was $1 / 1280$ for host cells, and it was used at final concentrations of $1 / 640,1 / 64$ and $1 / 6$. Ammonium sulphate was known to slow down or prevent the adsorption of T 2 coliphage on to Escherichia coli (French, Graham, Lesley \& Rooyen, 1952). Consequently, it was hoped that it might similarly affect the staphylococcal system. Therefore ammonium sulphate at a final concentration of $5 \%(\mathrm{w} / \mathrm{v})$ was tested for its ability to increase the titre of a staphylococcal phage $\mathbf{K}$ lysate when added after infection. The serum or ammonium sulphate solution was added to the culture 5 min. after phage infection of $10^{9}$ host cells $/ \mathrm{ml}$. by phage $\mathrm{K}$ at $1.5 \times 10^{9}$ particles $/ \mathrm{ml}$. The results of such an experiment are shown in Table 1.

Table 1. The effect upon final phage titre and appearance of the lysate of certain additions to cultures of Staphylococcus aureus with and without phage

Concentration of Staphylococcus aureus $10^{9}$ organisms $/ \mathrm{ml}$. Infective ratio (phage/host cells) $1 \cdot 5: 1$.

\begin{tabular}{|c|c|c|c|c|c|}
\hline $\begin{array}{c}\text { Tube } \\
\text { no. }\end{array}$ & $\begin{array}{c}\text { Presence } \\
\text { of } \\
\text { phage } \\
(+ \text { or }-)\end{array}$ & $\begin{array}{l}\text { Additions to } \\
\text { system } \\
\text { (final } \\
\text { concentration) }\end{array}$ & $\begin{array}{c}\text { Time of } \\
\text { addition } \\
\text { of additive } \\
\text { relative } \\
\text { to phage } \\
\text { infection } \\
\text { (min. + } \\
\text { or -) }\end{array}$ & $\begin{array}{l}\text { Phage } \\
\text { titre at } \\
24 \mathrm{hr} . \\
\left(+10^{10}\right)\end{array}$ & $\begin{array}{c}\text { Appearance of } \\
\text { lysate }\end{array}$ \\
\hline 1 & - & Nil & . & . & Very turbid \\
\hline 2 & - & Serum dil. $1 / 64$ & . & • & $\begin{array}{l}\text { Clear, organisms ag- } \\
\text { glutinated and } \\
\text { settled. Approx. } \\
\text { same turbidity as } \\
\text { no. } 1 \text { on shaking }\end{array}$ \\
\hline 3 & - & $\left(\mathrm{NH}_{4}\right)_{2} \mathrm{SO}_{4}, 5 \%(\mathrm{w} / \mathrm{v})$ & - & - & As no. 1 \\
\hline 4 & + & Nil & - & $1 \cdot 7,2 \cdot 0 *$ & Clear, slight sediment \\
\hline $\mathbf{5}$ & + & Serum dil. 1/640 & +5 & $\mathbf{3} \cdot \mathbf{3}$ & Clear, slight sediment \\
\hline 6 & + & Serum dil. $1 / 64$ & +5 & $\mathbf{2 \cdot 2}$ & Clear, slight sediment \\
\hline 7 & + & Serum dil. $1 / 6$ & +5 & $2 \cdot 3$ & Clear, slight sediment \\
\hline 8 & + & $\left(\mathrm{NH}_{4}\right)_{2} \mathrm{SO}_{4}, 5 \%(\mathrm{w} / \mathrm{v})$ & +5 & $6 \cdot 7$ & Clear, coarse sediment \\
\hline 9 & + & Serum dil. $1 / 64$ & -2 & $\mathbf{3} \cdot \mathbf{3}$ & Clear, slight sediment \\
\hline 10 & + & $\left(\mathrm{NH}_{4}\right)_{2} \mathrm{SO}_{4}, 5 \%(\mathrm{w} / \mathrm{v})$ & -2 & $<0 \cdot 1$ & Very turbid (no lysis) \\
\hline
\end{tabular}

The results obtained in several experiments showed that suitable additions of ammonium sulphate did increase the titre of the final lysate, while antiserum did not significantly affect the titre. Turbidity time curves showed that the ammonium sulphate concentration used had very little inhibitory effect upon the growth rate of the host, and addition of ammonium sulphate before adding the phage regularly prevented phage multiplication and lysis. These results are in keeping with the notion that the ammonium sulphate acts by slowing adsorption. This was tested by measuring the velocity constant $K$ 
(Adams, 1950) of the rate of adsorption of phage upon host at $37^{\circ}$ in broth containing varying amounts of added ammonium sulphate. Chloroform-killed staphylococci were used at a final concentration of $10^{8} / \mathrm{ml}$. in the experimental tubes. Tubes received $5 \mathrm{ml}$. broth, $1 \mathrm{ml}$. suspension of cocci and different volumes of $5 \%$ neutral ammonium sulphate in saline. The volume in each tube was made up to $10 \mathrm{ml}$. with saline, and $0.1 \mathrm{ml}$. phage suspension containing $10^{9}$ plaque-forming units $/ \mathrm{ml}$. added. The mixtures were then allowed to stand for $1 \mathrm{hr}$., and the unadsorbed phage then assayed. The results are shown in Fig. 1 which is typical of several experiments. The curve shows that

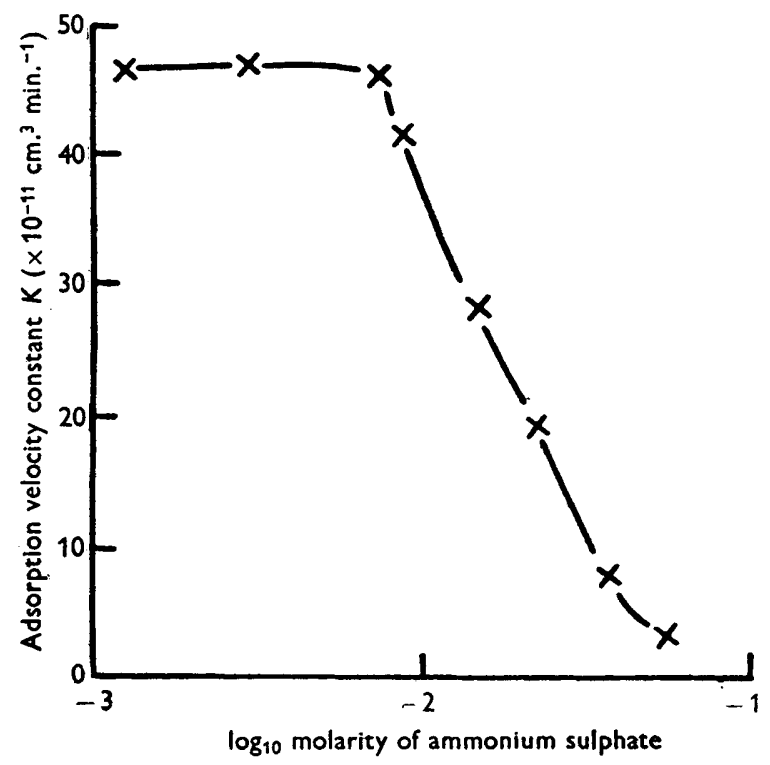

Fig. 1. The effect of varying concentrations of ammonium sulphate upon the velocity constant $(K)$ of the adsorption of staphylococcal phage $K$ on to host staphylococci. $K=2 \cdot 3 /(B) t \times \log P_{0} / P$ where $(B)=$ concentration of bacteria (no. cells $/ \mathrm{ml}$.), $t=$ time (min.), $P_{0}=$ phage particles $/ \mathrm{ml}$. at zero time, $P=$ phage particles $/ \mathrm{ml}$. not adsorbed at time $t$ min.

increasing concentrations of ammonium sulphate markedly decreased the adsorption rate of the phage upon its host. The optimal effect upon phage yield occurred beyond the higher limit of the experimental range shown, where the velocity constant was less than 1/100th of its normal value. Further experiments indicated that the optimal final concentration of ammonium sulphate for maximum lysate titre was at a concentration of $c \cdot 0 \cdot 1-0 \cdot 2 \mathrm{M}$ $(\mathbf{1} \cdot 5-2.5 \%, \mathrm{w} / \mathrm{v})$ according to the batch of broth used. Addition of ammonium sulphate at this concentration $2 \mathrm{~min}$. after phage inoculation regularly gave lysates with titres of between 1 and $4 \times 10^{11}$ particles $/ \mathrm{ml}$. Small variations in the ammonium sulphate concentration sharply affected the rate of lysis and the final titre. Lysis in the presence of ammonium sulphate was slower than in control cultures without it. One-step growth curves showed a slight increase 
in the latent period when the optimal concentration of ammonium sulphate was added, the burst size being the same as in controls without added ammonium sulphate. The increase in latent period was not considered sufficient to account for the slower lysis of cultures.

\section{DISCUSSION}

The results described here are in keeping with the hypothesis proposed; ammonium sulphate can decrease the rate of adsorption of staphylococcus $\mathbf{K}$ phage upon its host Staphylococcus aureus, and in suitable conditions this effect is paralleled by a marked increase in phage yield, after a delayed lysis. It is considered that the first effect is the cause of the second and that the following mechanism holds. The concentration of free titratable phage in a system of multiplying host cells is the resultant of two opposing processes: the liberation of phage into the medium or phage production $(P)$ and the loss of plaque-forming units or phage loss $(L)$. The phage loss $L$ initially occurs almost entirely by adsorption upon uninfected host cells, and later by adsorption upon uninfected, infected and dead host cells and bacterial debris, plus any other causes of phage inactivation or death. Immediately after a culture is infected with phage $\boldsymbol{L}>\boldsymbol{P}$ (since $\boldsymbol{P}$ at this time is zero) thus accounting for the usual fall in free phage titre at this stage. As phage multiplication proceeds $\boldsymbol{P}$ increases rapidly, becoming greater than $L$, and the concentration of free phage rises. In concentrated systems it seems that the increase of $\boldsymbol{P}$ becomes limited, possibly by nutritional factors, before the lysis of the culture. Phage loss by adsorption is proportional to the concentration of free phage, so that $L$ increases until $L=P$. This appears to occur in the system studied at phage concentrations of $c .10^{10} / \mathrm{ml}$, this being the ceiling titre at which phage production is balanced by phage loss. By adding ammonium sulphate to phage the adsorption velocity and consequently phage loss is decreased. Under these conditions the same rate of phage production will only be balanced by phage loss when there is a much higher concentration of free phage to compensate for the decrease in adsorption velocity; i.e. the ceiling titre will be higher.

The inability of host cell antiserum to increase the titre by decreasing phage adsorption is surprising in view of its effect in preventing phage adsorption to host in the $T$ coliphages (Delbrück, 1945). This difference was not investigated further, although it suggests that the phage adsorption site on the host cell is not covered by host-cell antiserum in the staphylococcal system.

A similar mechanism to the one proposed appears to be operating in experiments described by Bradley \& Boyd (1952). The results of these workers indicate that phage released by the lysing fraction of a culture of lysogenic Salmonella typhimurium is lost to the extent of $99.9 \%$ by re-adsorption on to phage-immune cells; this re-adsorption was prevented by Cetrimide at 1/10,000 dilution.

When lysis of the staphylococci occurred after the ceiling titre had been reached, there was no further rise in phage $\mathbf{K}$ titre; this phenomenon offers an 
alternative explanation for the results of Farrant \& Rountree (1953) with staphylococcus phage $3 \mathrm{~A}$. They concluded that release of this phage from its host preceded and was not synchronous with optical clearing of the culture, the release being due to bursting of the cells, while the cell membranes left were considered able to contribute to the same extent as the intact cells to the turbidity of the culture. However, simple rupture of staphylococcal membranes which allows cell contents to escape is known to result in a tenfold or greater decrease in turbidity (Hotchin, 1954). Similarly, phase-contrast microscopy readily differentiates ruptured from unruptured staphylococci (Hotchin, Dawson \& Elford, 1952). These differences are presumably due to the high refractive index of the bacterial cytoplasm when in the concentrated intracellular state. It is hard to visualize a change in permeability of the staphylococcal membrane which would allow the release of relatively large phage particles while retaining the bacterial cytoplasm. An alternative explanation for their results is that in Farrant \& Rountree's system the ceiling titre was reached before the culture cleared optically.

The observations described are obviously important to consider when large yields of phage are desired. It is possible that the effect may occur in animal virus systems, especially when conditions of growth (e.g. suspended cell cultures) approximate those of fluid bacteriophage cultures.

\section{REFERENCES}

Adams, M. H. (1950). Section I. Methods of study of bacterial viruses. Meth. med. Res. $2,19$.

Bradley, P. L. \& Boyd, J. S. K. (1952). Readsorption of phage produced in cultures of lysogenic strains of Salmonella typhi-murium. J. Path. Bact. 64, 891 .

DelbrücK, M. (1945). Effects of specific anti-sera on the growth of bacterial viruses (bacteriophages). J. Bact. 50, 137.

Farrant, J. L. \& Rountree, P. M. (1953). Electronmicroscopy of a staphylococcal bacteriophage. J. gen. Microbiol. 9, 288.

French, R. C., Graham, A. F., Lesley, S. M. \& Rooyen, C. E. van (1952). The contribution of phosphorus from $\mathrm{T}_{2} \mathrm{r}^{+}$bacteriophage to progeny. J. Bact. 64, 597.

Hotchin, J. E. (1954). The purification and electron microscopical examination of the structure of staphylococcal bacteriophage K. J. gen. Microbiol. 10, 250.

Hotchin, J. E., Dawson, I. M. \& Elford, W. J. (1952). The use of empty bacterial membranes in the study of the adsorption of staphylococcus $\mathrm{K}$ phage upon its host. Brit. J. exp. Path. 33, 177. 